\title{
A BIBLIOTECA COMO ESPAÇO DE APRENDIZAGEM E DE FORMAÇÃO DE COMPETÊNCIA INFORMACIONAL
}

\author{
THE LIBRARY AS A SPACE FOR LEARNING AND TRAINING \\ FOR INFORMATIONAL COMPETENCE
}

\section{BIBLIOTECA COMO ESPACIO DE APRENDIZAJE Y FORMACIÓN DE COMPETENCIA INFORMACIONAL}

\author{
Luciane Alves SAntini \\ Instituto Federal do Rio Grande do Sul (IFRS) \\ Cledes Antonio Casagrande \\ Universidade La Salle
}

Resumo Este artigo tem como objetivo analisar a biblioteca de uma instituição educacional como um possível espaço-tempo de desenvolvimento de aprendizagens e formação de competência informacional. Ele é oriundo de uma pesquisa, do tipo estudo de caso, realizada em um Programa de Pós-Graduação em Educação, cujo lócus analítico foi o Instituto Federal do Rio Grande do Sul - IFRS. A coleta de dados foi efetuada por meio da aplicação de questionário e de entrevista. A análise dos dados seguiu a técnica de análise de conteúdo. Os resultados da pesquisa apontaram cinco categorias de análise: acesso à informação; avaliação da informação; uso da informação; autonomia dos estudantes; possibilidades de atuação da biblioteca no desenvolvimento da competência informacional. Ademais, constatamos que a biblioteca necessita se adaptar à nova realidade das tecnologias digitais, atuando como um espaço formativo por meio de ações que levem ao desenvolvimento de aprendizagens significativas, de novos conhecimentos e da formação da competência informacional.

Palavras-chave: EducaÇão; Aprendizagem; Biblioteca; Letramento informacional. 
Abstract This article aims to analyze the library of an educational institution as a possible space-time of learning development and informational competence formation. It comes from a case-study research carried out in a Graduate Program in Education, whose analytical locus was the Federal Instituto do Rio Grande do Sul (IFRS). The data collection was performed through the application of a questionnaire and interview. Data analysis followed the technique of content analysis. The research results pointed to five categories of analysis: access to information; Evaluation of information; Use of information; Autonomy of students; Possibilities of the library's performance in the development of informational competence. In addition, we find that the library needs to adapt to the new reality of digital technologies, acting as a formative space through actions that lead to the development of meaningful learning, new knowledge and the formation of informational competence.

KeY-wORds: EdUCATION; LeARning; Libraries; Information Literacy.

Resumen Este artículo tiene como objetivo analizar la biblioteca de una institución educativa como un posible espacio-tiempo de desarrollo de aprendizajes y formación de competencia informacional. Es oriundo de una investigación, del tipo estudio de caso, realizada en un Programa de Postgrado en Educación, cuyo lócus analítico fue el Instituto Federal de Rio Grande do Sul - IFRS. La recolección de datos fue realizada a través de la aplicación de cuestionario y de entrevista. El análisis de los datos siguió la técnica de análisis de contenido. Los resultados de la encuesta apuntaron cinco categorías de análisis: acceso a la información; Evaluación de la información; Uso de la información; Autonomía de los estudiantes; Las posibilidades de actuación de la biblioteca en el desarrollo de la competencia informacional. Además, constatamos que la biblioteca necesita adaptarse a la nueva realidad de las tecnologías digitales, actuando como un espacio formativo por medio de acciones que lleven al desarrollo de aprendizajes significativos, de nuevos conocimientos y de la formación de la competencia informacional.

Palabras clave: Educación; Alfabetización informacional; Aprendizaje; Biblioteca.

\section{INTRODUÇÃo}

Este artigo exibe resultados de uma pesquisa, tipo estudo de caso, já concluída e apresentada ao PPG de Educação da Universidade La Salle. A pesquisa, que teve como campo empírico uma biblioteca do Instituto Federal do Rio Grande do Sul (IFRS), ${ }^{1}$ possuía o objetivo de investigar quais as possibilidades da biblioteca de uma instituição de ensino configurar-se como espaço-tempo de aprendizagem e de desenvolvimento de competência informacional ${ }^{2}$ para os seus alunos.

1 Ressaltamos que a autora da pesquisa atua como bibliotecária em uma instituição de educação, percebendo em sua prática quotidiana algumas dessas dificuldades mencionadas.

2 A expressão information literacy é amplamente utilizada no Brasil como "competência informacional", segundo Guasque (2010, p. 83). 
Entendemos que essa temática possui relevância no campo educacional e viabilidade como pesquisa visto as dificuldades demonstradas pelos estudantes na seleção e utilização das informações disponibilizadas, especialmente por meio das tecnologias digitais. Além disso, percebemos que a facilidade de acesso à informação tornou-se um ponto crucial para o desenvolvimento do conhecimento na sociedade atual, porém ela trouxe um novo questionamento sobre a função, a organização e a ação das bibliotecas das instituições de ensino. Desse modo, entendemos ser pertinente refletir acerca de qual é o papel das bibliotecas e dos bibliotecários das instituições de ensino no desenvolvimento dos discentes, auxiliando-os a que se tornem capazes de buscar e selecionar informações válidas e seguras, além de serem capazes de transformar tais informações em conhecimento.

$\mathrm{Na}$ pesquisa em questão, partimos da seguinte situação problema: Quais as possibilidades da biblioteca de uma instituição de ensino se configurar como espaço-tempo de aprendizagens e de desenvolvimento de competências informacionais?

A metodologia utilizada foi um estudo de caso que, de acordo com Yin (2001, p. 32), “[...] é uma investigação empírica que investiga um fenômeno contemporâneo dentro de seu contexto da vida real, especialmente quando os limites entre o fenômeno e o contexto não estão claramente definidos". A coleta de dados ocorreu a partir da aplicação de questionário aos docentes e também de entrevista com uma bibliotecária, ambos do Campus Restinga, do Instituto Federal do Rio Grande do Sul (IFRS).

Para a análise dos dados, nos ancoramos na técnica de análise de conteúdo de Bardin (2006), a partir da qual se busca descrever o conteúdo emitido no processo de comunicação. A referida “[...] técnica é composta por procedimentos sistemáticos que proporcionam o levantamento de indicadores (quantitativos ou não) permitindo a realização de inferência de conhecimentos" (CAVALCANTE; CALIXTO; PINHEIRO, 2014, p. 14). Como resultado da análise dos dados, evidenciamos cinco categorias descritivas, que serão abordadas no decorrer do artigo.

Com o intuito de retratar a pesquisa realizada, estruturamos este artigo em três partes. $\mathrm{Na}$ primeira, apresentamos a revisão de literatura realizada, na qual acentuamos a relação entre os processos de aprendizagem e a formação de competências, especialmente a competência informacional. Na segunda, descrevemos a análise e discussão dos dados, evidenciando cinco categorias analíticas oriundas da pesquisa. Finalmente, apontamos alguns elementos que consideramos necessários para que uma biblioteca se torne um espaço formativo, contribuindo na aprendizagem da competência informacional e no desenvolvimento da autonomia dos estudantes.

\section{REVISÃo DE LITERATURA}

O tema e o problema de pesquisa nos levaram a buscar referenciais teóricos sobre a relação entre os processos de aprendizagem e o desenvolvimento de competências, especialmente a competência informacional. Esses referenciais, possibilitaram, posteriormente, 
que compreendêssemos melhor o papel da biblioteca e dos bibliotecários de uma instituição de ensino, em especial a função formativa que eles podem exercer por meio das suas ações quotidianas. Por isso, na sequência, abordaremos alguns referenciais teóricos utilizados, sobremaneira aqueles relacionados aos processos de aprendizagem [i] e à formação de competência informacional [ii].

\section{[i] Aprendizagem}

O processo de aprendizagem é fundamental à formação e ao desenvolvimento dos sujeitos e da própria sociedade (EDER, 2001). Esse processo se desenrola ao longo da vida, de forma contínua e ininterrupta, no qual novos elementos são integrados a um eu que vai se estruturando gradativamente (HABERMAS, 2003 e 2012; PIAGET, 1978 e 2007). Segundo Marques, o homem é um ser que aprende e:

[...] sua existência não é por inteiro dada ou fixa; ele a constrói a partir de imensa gama de possibilidades em aberto. Nasce no seio de uma cultura viva, que só é tal à medida que assumida como desafio de permanente reconstrução pela atribuição dos sentidos que imprime a seu convívio em sociedade e na estruturação da própria personalidade (MARQUES, 2000, p. 15).

Uma das mais importantes aprendizagens do ser humano relaciona-se à construção e reconstrução do conhecimento. Consoante a Piaget, entendemos que o processo de construção do conhecimento deriva da relação "[...] entre o sujeito que busca conhecer e o objeto de ser conhecido" (PALANGANA, 2001, p. 29). Na perspectiva apontada por Piaget (2007), o processo de desenvolvimento cognitivo do ser humano ocorre ao longo de quatro fases, nas quais a maturação e a formação das estruturas cognitivas fornecem as condições necessárias para uma aprendizagem efetiva (MARQUES, 2000).

A teoria piagetiana demonstrou a gênese do conhecimento pela observação do desenvolvimento cognitivo da criança respondendo à “[...] questão fundamental (de ordem epistemológica) que se refere à natureza da inteligência, qual seja: como se constrói o conhecimento?" (PALANGANA, 2001, p. 71).

De acordo com Palangana, na perspectiva de Piaget:

[...] conhecer significa organizar, estruturar e explicar o real a partir das experiências vividas. Conhecer é modificar, transformar o objeto; é compreender o mecanismo de sua transformação e, consequentemente, o caminho pelo qual o objeto é construído. O conhecimento é sempre produto da ação do sujeito sobre o objeto. Neste sentido, a operação é a essência do conhecimento: a ação interiorizada modifica o objeto do conhecimento, impondo-lhe uma ordenação no espaço e no tempo. Orientado pelos princípios da biologia, Piaget viu na coordenação funcional da ação adaptativa a origem de todo conhecimento (PALANGANA, 2001, p. 71-72). 
A partir dos estudos de Piaget, o desenvolvimento cognitivo passa a ser entendido como um processo contínuo, que implica assimilação e equilibração. Assim, Piaget reconhece que:

O conhecimento tem início quando o recém-nascido age, assimilando alguma coisa do meio físico ou social; e esse conteúdo assimilado, ao entrar no mundo do sujeito, provoca, aí, perturbações, pois traz consigo algo novo, para o qual a estrutura assimiladora não tem instrumento. Urge, então, que o sujeito refaça seus instrumentos de assimilação em função da novidade. Esse refazer do sujeito sobre si mesmo é a acomodação. É esse movimento, essa ação que refaz o equilíbrio perdido; porém, o refaz em outro nível, criando algo novo no sujeito. Esse algo novo fará com que as próximas assimilações sejam diferentes das anteriores, sejam melhores: equilibração majorante, isto é, o novo equilíbrio é mais consistente que o anterior (BECKER, 2001, p. 25).

Piaget (2007) dividiu o desenvolvimento cognitivo em quatro estágios, que se sucedem progressivamente: a) o sensório-motor - do nascimento aos 2 anos de idade; b) o pré-operacional - dos 2 aos 7 anos de idade; c) o estágio das operações concretas - dos 7 aos 12 anos de idade; d) o estágio das operações formais, que corresponde ao período da adolescência - dos 12 de idade em diante. Ao analisar esses estágios, Palangana (2001) afirma que:

Cada período define um momento do desenvolvimento como um todo, ao longo do qual a criança constrói determinadas estruturas cognitivas. Um novo estágio se diferencia dos precedentes pelas evidências, no comportamento, de que a criança dispõe de novos esquemas, contendo propriedade funcionais diferentes daquelas observadas nos esquemas anteriores (p. 23-24).

O avanço para o estágio seguinte depende do que foi desenvolvido no anterior, determinando que o processo de desenvolvimento cognitivo se realiza de forma sequencial, no qual cada estágio "[...] resulta necessariamente do precedente (exceto o primeiro) e, ao mesmo tempo, prepara o seguinte" (RIES, 2004, p. 107). Essa dependência da fase anterior condiciona a passagem de fase por fase para que se alcance a maturidade das estruturas. No entanto, observa-se que a passagem de um estágio para o outro depende do ritmo individual na aquisição de novas habilidades.

[...] o crescimento intelectual tem o seu ritmo e os seus caminhos necessários (créodos), do mesmo modo que o crescimento físico, o que não significa que bons métodos pedagógicos não possam acelerar um pouco as idades críticas; mas é importante frisar que essa aceleração não será indefinida (PIAGET, 1978, p. 32).

Percebemos que é por intermédio de um processo individual que se constrói o conhecimento e que isso resulta de uma ação do sujeito sobre o objeto, na qual as estruturas evoluem sequencialmente nas fases descritas por Piaget. 
Reconhecemos em Piaget um entendimento semelhante ao de Kant (2005), no que se refere à relação entre sujeito e objeto na construção do conhecimento. Ambos admitem "[...] a existência de estratégias (condições) inatas - próprias do sujeito - por meio das quais tem início o processo de interação e consequentemente o desenvolvimento da estrutura cognitiva" (PALANGANA, 2001, p. 39). Dessa maneira, a teoria de Piaget aproxima-se da teoria de Kant no que diz respeito à ênfase dada à atividade do sujeito e também na necessidade de explicar racionalmente esse processo. Temos aqui, desse modo, uma clara relação entre o processo de aprendizagem e o desenvolvimento da autonomia e da capacidade de aprender a aprender.

Como já afirmamos, o ser humano é um ser que aprende, que constrói e reconstrói a si mesmo e ao seu próprio mundo, por meio de processos de aprendizagem. Para que conquiste a autonomia, é necessário que ele desenvolva a capacidade reflexiva e estabeleça relações de "[...] intercâmbio entre os sujeitos no sentido de transformação de sua autocompreensão como pessoas que vivem com outros, que respeitam as regras estabelecidas e o princípio do entendimento mútuo" (PAVIANI, 2013 p. 87-88).

Os processos de aprendizagem, como instâncias de constituição dos sujeitos e das sociedades, precisam desenvolver uma série de capacidades ou competências nos sujeitos aprendentes. Nessa perspectiva, entendemos que os processos formativos devem também ser orientados ao desenvolvimento da autonomia dos estudantes. Para Kant (2005, p. 63), a autonomia só é alcançada com a "[...] saída do homem de sua menoridade, da qual ele próprio é culpado. A menoridade é a incapacidade de fazer uso de seu entendimento sem a direção de outro indivíduo".

Já na visão de Adorno (1995, p. 143), a "[...] emancipação significa o mesmo que conscientização, racionalidade" e capacidade de posicionar-se criticamente diante de uma situação concreta da vida. Autonomia e emancipação dependem, dentre outros fatores, da "[...] instrução e da educação escolar e sociocultural, através da leitura, que produz a capacidade de reflexão crítica e o entendimento racional do mundo" (VILELA, 2007, p. 230). Dessa forma, entendemos que a instituição educativa desempenha um papel essencial no desenvolvimento da capacidade de pensar e de tomar decisões dos alunos, permitindo que se torne capaz de questionar e refletir, buscar o que deseja e aprender a aprender de forma independente e na relação com os outros.

No horizonte do que já temos postulado, reconhecemos que a experiência formativa depende de vários fatores e é central ao desenvolvimento da capacidade de aprender a aprender ou da competência de se autoformar. Além disso, acreditamos que a formação para a reflexão crítica e para o desenvolvimento da autonomia pode ocorrer em múltiplos espaços e tempos no ambiente escolar. Em outras palavras, partimos do pressuposto de que a instituição escolar, em seu todo, deve consistir em espaço-tempo privilegiado à realização de experiências formativas. Além disso, os processos educacionais necessitam estar fundamentados na aprendizagem, com o fim de possibilitar o desenvolvimento de competências; e a instituição educativa tem como uma de suas finalidades possibilitar o desenvolvimento de competências (MACEDO, 1999). 


\section{[ii] Formação de competência informacional}

De acordo com o que temos argumentado, a educação tem como uma de suas principais finalidades a promoção da aprendizagem e o desenvolvimento do ser humano. Assim, acreditamos que a valorização dos estudantes no ambiente educacional, onde eles próprios sejam protagonistas da construção do conhecimento, possibilita que desenvolvam a "[...] necessária autonomia que permita à pessoa atuar de forma consciente e transformadora na realidade, da mais próxima à mais distante, da mais específica à mais ampla" (BOFF; ZANETTE, 2010). Por isso, procuramos definir, no âmbito desta pesquisa, o conceito de competência, aliado à aprendizagem, a fim de argumentar em prol de como a biblioteca, e as pessoas que nela atuam, podem exercer o papel de contribuir no desenvolvimento da competência informacional.

Conforme Perrenoud (1999, p. 20-21), "[...] as competências, no sentido que será aqui utilizado, são aquisições, aprendizados construídos, e não virtualidades da espécie". Para o desenvolvimento de competências, precisamos de estímulos e de formas de aprendizados que nos auxiliem nessa ação, sendo necessário aprendermos a identificar e localizar informações pertinentes (PERRENOUD, 1999). Além disso, precisamos aprender esquemas de mobilização dos conhecimentos que nos possibilitem utilizá-los de forma intensa, caso contrário, estaremos apenas mobilizando conhecimentos sem formar competências. Para que consigamos desenvolver competências, precisamos "[...] mobilizar recursos, cooperar, coordenar pontos de vista, envolver-se e se deixar ser envolvido, transformar em vontade aquilo que começou como uma intenção e que há de terminar como uma boa realização" (MACEDO, 2008).

O desenvolvimento de competências envolve vários aspectos, como a formação de esquemas, a mobilização deles e, também, a estabilização dessas competências. A estabilização só acontece, segundo Perrenoud $(1999$, p. 23), “[...] quando a mobilização dos conhecimentos supera o tatear reflexivo ao alcance de cada um e aciona esquemas constituídos". Esse processo de estabilização assemelha-se com a teoria de Piaget, que assinala uma dependência entre os diversos estágios de desenvolvimento cognitivo, isto é, para se avançar para o próximo estágio, é necessário que o anterior esteja consolidado.

Podemos sintetizar o conceito de competências, segundo Macedo (2002), com base nas características de tomada de decisão, de mobilização de recursos e do saber agir, no sentido de construção, de coordenação e de articulação de esquemas de ação ou de pensamento. Além disso, podemos relacionar competência à capacidade de utilizar os conhecimentos no momento certo e com a capacidade de "[...] relacionar, pertinentemente, os conhecimentos prévios e os problemas [...]" (PERRENOUD, 1999, p. 32).

Nesse contexto, entendemos que a escola tem como desafio possibilitar aos alunos que os objetivos e conteúdos sejam transmitidos "[...] de um modo interdependente ao desenvolvimento dos recursos ou procedimentos para essa assimilação" (MACEDO, 2008 s.p.), proporcionando, com isso, uma aprendizagem significativa. E, dessa maneira, ainda conforme Macedo (2008, s.p.), a escola precisa "[...] antecipar, instruir, transmitir, hoje, aquilo que as crianças hão de precisar mais tarde, quando se tornarem adultas, quando 
forem nos substituir (espera-se, para melhor). Considerar o ser como tornar-se pede uma reflexão sobre as relações entre presente, passado e futuro".

A informação sempre ocupou um papel importante no desenvolvimento da sociedade, mas atualmente ela passa a ocupar um lugar de destaque. Conforme Dudziak (2003, p. 23), "A informação passou a ser reconhecida como elemento-chave em todos os segmentos da sociedade. Tal é sua importância que se manter informado tornou-se indicador incontestável de atualidade e sintonia com o mundo". Nesse contexto, precisamos não só ter acesso à informação, mas, principalmente, sermos capazes de nos relacionarmos com a informação de forma crítica e conseguir transformá-la em conhecimento. Segundo Varela (2005, p. 2), estamos inseridos em uma nova "[...] sociedade que busca o conhecimento e novos modelos que possibilitem interpretar e compreender o mundo". Isso fez que novas formas de interação surgissem e, assim, precisamos repensar o papel dos profissionais que fazem a mediação entre o pesquisador e a informação, sobretudo no ambiente escolar.

Bari (2010) ressalta que a educação tem papel importantíssimo na capacitação das pessoas para que possam usufruir de forma competente do conhecimento produzido pela humanidade. Para tal, é necessário que "[...] as pessoas adquiram competências para localizar, avaliar e usar informações, o que implica, por parte dos bibliotecários, em ações mais complexas, pois as pessoas, além de tornarem-se leitores, necessitam ser competentes para aprender por meio da informação" (CAMPELO, 2010, p. 185). A competência informacional pode auxiliar no desenvolvimento de pessoas aptas a utilizarem a informação de maneira autônoma e eficiente.

Assim, entendemos que um modo de auxiliar na formação dos estudantes consiste em proporcionar situações de aprendizagem que os auxiliem a desenvolver certa classe de competências, especialmente a competência informacional, no que se refere ao papel da biblioteca e dos bibliotecários. Ao desenvolver essas competências, também se busca estimular a autonomia dos discentes não só no que diz respeito à busca e ao acesso, mas principalmente no emprego da informação recuperada. Dessa forma, a competência em informação é mais do que somente acessar a informação, mas sim compreendê-la e incorporá-la aos conhecimentos de cada um.

A Associação Bibliotecária Americana (ALA) lançou em 1989, no relatório final do Presidential Comunitee on Information Literacy, o seguinte entendimento do que pressupõe ser uma pessoa competente informacionalmente:

[...] a pessoa deve ser capaz de reconhecer quando necessita de informação e possuir a capacidade de localizar, avaliar e utilizar de forma eficaz a informação necessária. [...] Os indivíduos competentes em informação são aqueles que aprenderam a aprender (ALA, 1989, tradução do autor).

Como a definição da ALA é bastante ampla, alguns autores da área passaram a utilizar a definição do que é competência informacional do seguinte modo: 
[...] um processo de aprendizagem contínuo que envolve informação, conhecimento e inteligência. É transdisciplinar, incorporando um conjunto integrado de habilidades, conhecimentos, valores pessoais e sociais, permeia qualquer fenômeno de criação, resolução de problemas e/ou tomada de decisões (DUDZIAK, 2003, p. 29).

Kuhlthau (1999) define a competência em informação como sendo a habilidade individual de construir sentido, estando inserido em um ambiente rico em informação. Essa definição pode ser complementada com a afirmação de Campello (2010), que acredita que é imprescindível estimular os alunos a pensarem de forma lógica e criativa.

Quanto ao papel da biblioteca no desenvolvimento dessas competências, concordamos com a afirmação de Dudziak (2001, p. 73), que "[...] as bibliotecas enfrentam o desafio de se transformarem de mero repositório de informações, em agentes provocadores de mudanças educacionais". Para tanto, é necessário que haja uma integração com as demais áreas ligadas ao ensino-aprendizado e que esses profissionais estejam dispostos a trabalhar de forma construtivista para capacitar os alunos nessas novas formas de acesso, recuperação e avaliação da informação.

Além disso, a preocupação dos bibliotecários em auxiliar seus usuários sempre esteve presente, inicialmente com a educação de usuários e as atividades de instrução bibliográfica. Campelo $(2009$, p. 38) reforça essa ideia a partir das origens da biblioteconomia na prática da educação de usuários, quer dizer, na capacitação para a utilização do acervo da biblioteca, afirmando que "[...] na concepção biblioteconômica, essa necessidade estava baseada na premissa de que o conhecimento possa ser comunicado, isto é, que o usuário possa aprender com a informação". Esses serviços buscam, ainda hoje, instrumentalizar o usuário no uso da coleção e das fontes de informação. Já a competência informacional, na concepção de Dudziak (2001, p. 59), vai além da instrumentalização da técnica de busca, pois " [...] se refere ao aprendizado ao longo da vida, assumindo que os processos investigativos e de construção de conhecimento permeiam todas as ações, são aplicáveis a qualquer situação, seja junto a sistemas formais, seja junto a sistemas informais". A competência informacional deve preparar o usuário para procurar pela informação, mas também para como ele utilizará a informação recuperada, assim como habilitá-lo a pesquisar em várias fontes, sabendo usar a informação recuperada de forma a elaborar um texto próprio (BARI, 2010). Assim, acreditamos que a competência informacional relaciona-se de forma direta:

[...] ao aprendizado e à capacidade de criar significado a partir da informação. Pessoas competentes em informação reconhecem sua necessidade, sabem como e onde achar a informação, sabem avaliar e selecionar as informações mais relevantes, sabem organizar a informação de modo a criar novas idéias e interpretações, sabem usar a informação para a construção de conhecimentos importantes para o bem comum (DUDZIAK, 2001, p. 61).

Além disso, Dudziak (2001) destaca a concepção do movimento da competência informacional no estímulo ao aprender a aprender, levando o pesquisador a procurar o apren- 
dizado ao longo da vida. Assim, a competência informacional "[...] compreende não só a capacitação no uso das ferramentas de recuperação da informação, como também o entendimento do uso dos recursos e fontes, explorando os conceitos fundamentais e as habilidades ligadas à tecnologia da informação [...]" (DUDZIAK, 2001, p. 62). Por conseguinte, a competência informacional pode contribuir no êxito da aprendizagem e da autonomia do aluno. Além disso, acreditamos que pode auxiliar no desenvolvimento do hábito da leitura, do pensamento crítico e de se manter atualizado, empregando adequadamente ferramentas e estratégias de busca (DUDZIAK, 2001).

No entanto, para que o desenvolvimento da competência seja possível Kuhlthau (1999, p. 9) acredita que é necessário que as instituições educativas se adaptem para que consigam "[...] preparar seu aluno para o uso inteligente da informação disponível através da tecnologia [...]. O processo de aprendizagem a partir de uma ampla variedade de fontes é o desafio crítico para as escolas na sociedade da informação". Para Silva et al. (2005, p. 32), "Decorre daí um novo conceito que vem ganhando a forma de movimento mundial de bibliotecários, conscientes da necessidade de mudança na relação biblioteca-aprendizagem na sociedade contemporânea, que põe ênfase no acesso à informação nas redes". Além disso, Souza $(2009$, p. 22) destaca que o ensino atual está “[...] voltado para os processos de construção de conhecimento, com ênfase no 'aprender a aprender' como um processo contínuo que depende da competência do aluno" e essa competência tanto no uso quanto na apropriação é que fará que a informação seja transformada em conhecimento.

Também acreditamos na relevância de que as bibliotecas sejam "[...] espaços de mediação e produção de sentido, nos quais ocorre a articulação entre o produtor (autor) e o receptor (usuário) [...]" e onde o bibliotecário passa a "[...] ser o mediador, garantindo condições de adequação entre a informação recebida/recuperada e o usuário para que ela possa ser apropriada e transformada em conhecimento" (SOUZA, 2009, p. 28). Nesse caso, acrescenta Souza (2009, p. 28), “[...] o bibliotecário mediador estará propiciando 'espaço' de aprendizagem durante a realização de suas pesquisas".

De acordo com Kuhlthau (1999, p. 10), o “[...] papel do bibliotecário é colaborar no ensino e aprendizagem, fornecer acesso à informação e gerenciar o programa da biblioteca", possibilitando o desenvolvimento da competência informacional. Isso vem ao encontro, segundo Dudziak (2003), dos conceitos trabalhados anteriormente, no que diz respeito a ações de estímulo à formação de alunos autônomos na busca, recuperação e utilização da informação. Para isso, a biblioteca precisa ser proativa, conforme Silva et al. (2005), e se inserir nas novas demandas de informação, atuando como uma facilitadora de novas aprendizagens. De maneira ainda mais ampla, Kuhlthau (1999, p. 10) esclarece que a "[...] competência é habilidade de construir sentido por si mesmo, em um ambiente rico em informação". Assim, acreditamos que a biblioteca pode ser um espaço de aprendizagem com a atuação do bibliotecário como mediador auxiliando dessa forma na: 
cia de sala de aula. Tal aprendizagem exige revisão da concepção de ensino-aprendizagem e a necessidade de desenvolvimento do pensamento reflexivo (GUASQUE, 2012, p. 159).

Destacamos que para se exercer de fato esse papel é necessário que haja uma parceria entre os profissionais, como reforça Campelo (2009, p. 46), "Na cooperação aumenta o relacionamento entre bibliotecário e professor, que trabalham juntos para ampliar as oportunidades de aprendizagem dos alunos".

\section{ANÁLISE E DisCuSSÃo dOS DADOS}

A pesquisa aqui relatada foi realizada a partir do estudo de caso da biblioteca do Campus Restinga/IFRS. Cabe esclarecer algumas peculiaridades da delimitação desse campo empírico, pois o IFRS é uma instituição participante da Rede Federal de Educação Profissional, Científica e Tecnológica (Rede Federal EPCT), que foi criada por força de lei em $2008 .{ }^{3}$ Essa rede se caracteriza por atender a tipos de públicos diferenciados, abrangendo cursos técnicos (integrado, subsequente, concomitante), licenciaturas, graduações tecnológicas, especializações, mestrados profissionais e doutorados, além de cursos profissionalizantes de formação inicial e continuada e o Programa de Educação de Jovens e Adultos (PROEJA). Devido a essa diversidade de níveis educacionais, as suas bibliotecas transitam entre biblioteca universitária e biblioteca escolar, não se limitando a qualquer das duas, mas atuando em ambas, gerando assim um tipo misto de biblioteca. Esse tipo de funcionamento é esclarecido por Teixeira $(2015$, p. 72$)$, ao afirmar que “[...] no Instituto coexistem, no mesmo espaço físico, dois tipos de bibliotecas sendo: as bibliotecas universitárias que atendem, principalmente, o público universitário; e as bibliotecas escolares, que são voltadas para os usuários oriundos do ensino médio-técnico". Dessa forma, no âmbito da pesquisa que realizamos, adotamos a definição de biblioteca multinível.

$\mathrm{Na}$ coleta de dados, aplicamos um questionário, que foi respondido por 17 docentes do IFRS, perfazendo um total de $28,3 \%$ da totalidade dos docentes, e uma entrevista com a bibliotecária dessa instituição de ensino. ${ }^{4}$ Para a análise dos dados, foi utilizada a técnica de análise de conteúdo de Bardin (2006), que resultou em cinco categorias de análise: acesso à informação, avaliação da informação, uso da informação, autonomia dos estudantes e possibilidades de atuação da biblioteca no desenvolvimento da competência informacional. $\mathrm{Na}$ análise dessas categorias, realizamos a triangulação dos dados relacionando o referencial teórico com os dados oriundos do questionário e da entrevista.

A partir da análise dos dados obtidos, verificamos que na percepção dos docentes a biblioteca consiste em um espaço de estudo, de pesquisa e, sobretudo, de consulta ao acervo

3 A Rede EPCT foi criada por força de lei e determinou a implantação dessas instituições por todo território brasileiro - Lei n. 11.892, de 29 de dezembro de 2008 (BRASIL, 2008).

4 Os participantes do estudo assinaram Termo de Livre Consentimento Esclarecido por meio do qual concordam em participar voluntariamente do questionário ou da entrevista. Além disso, temos autorização por escrito da Direção do IFRS/Campus Restinga para a realização da pesquisa e divulgação dos resultados. 
local. No que se refere à biblioteca do IFRS/Campus Restinga e à sua equipe, são tecidos muitos elogios, especialmente pela disponibilidade e iniciativa. No entanto, parece haver certo desconhecimento da potencialidade da biblioteca e da possibilidade de atuar na capacitação e formação dos estudantes, de modo complementar aos conteúdos desenvolvidos em sala de aula.

Apresentaremos, agora, cada uma das categorias que emergiram da coleta e análise dos dados:

\section{a) primeira categoria: acesso à informação}

Os dados analisados demonstram que os alunos procuram a biblioteca para realizar pesquisas motivados pela necessidade de sala de aula e que, em geral, restringem suas pesquisas aos livros do acervo. Obtivemos dados dissonantes entre os relatos dos questionários e da entrevista. Nos questionários, os educadores afirmam que a biblioteca auxilia no aprofundamento dos conteúdos desenvolvidos em sala de aula. Entretanto, na entrevista com a bibliotecária, percebemos que esse aprofundamento estaria restrito à consulta à bibliografia do curso e ao uso do espaço. Na entrevista, a questão do acesso é relatada unicamente na forma de treinamento ao acesso do portal de periódicos CAPES, não havendo mais qualquer atividade que denote ações relacionadas ao acesso.

Não observamos, em ambos instrumentos de coleta de dados, manifestações referentes à necessidade de ampliação das fontes de informação. Também não foi possível encontrar qualquer demonstração referente à possibilidade da biblioteca atuar como um espaço pedagógico integrado às atividades de sala de aula e capaz de auxiliar no desenvolvimento dos alunos nas questões de acesso à informação. Em suma, os dados do questionário e da entrevista apontam que a questão do acesso à informação se restringe à disponibilização do acervo, à capacitação no portal de periódicos CAPES e ao auxílio àqueles alunos que procuram a biblioteca.

\section{b) segunda categoria: avaliação da informação}

Os dados coletados nos questionários demonstram a existência de dificuldades dos alunos em avaliar as fontes de informação, bem como, a utilização frequente da ferramenta Google para realizar suas pesquisas. Com isso, eles acabam usando o primeiro resultado da busca, sem nenhuma verificação de credibilidade. A partir da análise dos instrumentos de pesquisa, é possível concluir que a única ação no sentido de capacitar os alunos se dá na disciplina de metodologia, que ocorre no final dos cursos. Entendemos que a capacitação e o esclarecimento referentes à avalição de fontes poderia minimizar o problema levantado pelos docentes, evitando também que os alunos utilizem sem critérios o primeiro resultado encontrado.

Destacamos também alguns relatos que evidenciam que os alunos do Ensino Médio têm mais dificuldades do que aqueles do Ensino Superior. Esse é um dado que constatamos no referencial teórico, em relação à importância da adequação da formação ao nível de desenvolvimento cognitivo do estudante (PIAGET, 2007) e ao contexto no qual ele está inserido. Esse fato demonstra a necessidade de que sejam desenvolvidas ações de capacitação e de 
desenvolvimento da competência informacional ao longo da vida escolar do aluno. Somente com um trabalho de acompanhamento adequado a cada nível de aprendizagem será possível superar as dificuldades relatadas em relação à capacidade de avaliar as informações disponíveis, denotando que o sujeito adquiriu competência informacional e autonomia.

\section{c) terceira categoria: uso da informação}

Os resultados observados nessa categoria se assemelham aos resultados da categoria anterior, pois apuramos que os docentes são os únicos responsáveis pela capacitação dos alunos, nas aulas de metodologia. $\mathrm{Na}$ análise do questionário, obtivemos tanto dados que demonstram que os alunos tratam a informação de forma adequada, mas possuem dificuldade na elaboração de textos, quanto manifestações a respeito da utilização demasiada do recurso de copiar e colar, que contradizem os dados teóricos sobre a adequada utilização da informação. Esses dados nos remetem para a questão do plágio e à necessidade de formar os estudantes para uma postura ética, crítica e reflexiva diante dos conteúdos ou temas abordados. Entendemos que a elaboração de textos críticos, que observem as questões éticas do uso da informação, necessita ser fomentada de forma ampla e constante com os discentes.

\section{d) quarta categoria: autonomia dos estudantes}

$\mathrm{Na}$ coleta de dados, procuramos verificar as percepções dos docentes e da bibliotecária referentes ao desenvolvimento da autonomia dos estudantes. Destacamos, nas respostas do questionário, a relação entre a competência no processo de pesquisa e a autonomia. Para os docentes, essa relação é perceptível, pois alunos que demonstram ter uma competência informacional mais desenvolvida também possuem mais autonomia no gerenciamento da aprendizagem. Segundo os dados obtidos, observamos que os alunos que explicitam essas características têm o hábito de pesquisar, conseguem selecionar melhores fontes e elaboram textos de melhor qualidade. Além disso, na percepção dos educadores, esses estudantes demonstram ter um maior comprometimento, organização e discernimento quanto ao próprio processo formativo.

Apesar desse reconhecimento por parte dos docentes, a bibliotecária relatou que não existe uma prática institucional sistemática, com a biblioteca, que focalize a formação da competência informacional dos estudantes e, por consequência, auxilie na formação da autonomia e da capacidade de reflexão crítica. Entendemos que o desenvolvimento da competência informacional e da autonomia faz que tenhamos pessoas com maior capacidade de questionamento e de reflexão, capacidade de aprender a aprender e, assim, possibilidade de se manter aprendendo ao longo da vida.

\section{e) quinta categoria: possibilidades de atuação da biblioteca no desenvolvi- mento da competência informacional}

Ao longo da pesquisa, procuramos demonstrar a importância do desenvolvimento de práticas institucionais que favorecessem a atuação conjunta dos docentes e da biblioteca, tornando a biblioteca uma extensão da sala de aula. Percebemos alguns fatores que dificul- 
tam que isso aconteça, como a falta de uma posição institucional clara, a total autonomia dos docentes e o foco de atuação dos profissionais das bibliotecas, mais ocupados em compor e gerenciar o acervo por meio da aquisição das bibliografias dos níveis superiores, em função das visitas de avaliação de cursos realizadas pelo MEC.

Destacamos as manifestações dos docentes sobre a possibilidade da biblioteca realizar capacitações para auxiliar no desenvolvimento da competência informacional dos alunos. Nessas manifestações, houve o reconhecimento da importância de iniciativas que poderiam ser desenvolvidas pela biblioteca e foram elencadas algumas atividades que, na percepção deles, melhor se adaptariam a essa finalidade. Entre os dados obtidos no questionário, percebemos que as maiores demandas são referentes ao desenvolvimento de ações de capacitação dos estudantes na realização de pesquisas acadêmicas, por intermédio de oficinas de pesquisa, de normalização e da qualificação em estratégias de pesquisa.

No entanto, na prática diária, constatamos que parece não existir comunicação entre os docentes e a biblioteca no sentido de elaborar ações conjuntas para a formação dos alunos. Na entrevista, foi possível observar que, mesmo em ações cotidianas, como levar os alunos para o espaço da biblioteca para a utilização dos livros do acervo, não é realizada qualquer combinação prévia com a bibliotecária. Esse procedimento reforça a visão da biblioteca como um repositório de informações na qual se fazem pesquisas no acervo físico, sem a mediação do bibliotecário e sem utilizar nenhum recurso a não ser o acervo.

A biblioteca do Campus Restinga oferece poucos treinamentos para os alunos, mas tem uma forte atuação individual com os alunos que frequentam seus espaços em busca de informações ou com aqueles que solicitam ajuda. Essa atuação individual está relacionada à prática de educação de usuários e ao serviço de referência, abordado no referencial teórico.

No entanto, para o desenvolvimento da competência informacional e a autonomia do estudante, entendemos ser necessário o desenvolvimento de atividades diversificadas e sequenciais. Essas atividades permitem ao estudante adquirir a destreza e o conhecimento para seguir aplicando essas habilidades e competências ao longo da vida. Reforçamos ainda o necessário apoio institucional para a mudança da percepção da biblioteca e para que ela se torne um espaço pedagógico. Além disso, destacamos a necessidade da instituição desenvolver políticas que estimulem o trabalho em conjunto entre docentes e os bibliotecários.

Dessa forma, podemos concluir que a biblioteca escolhida para realizarmos este estudo de caso ainda não atua em plenitude como um espaço pedagógico nem trabalha especificamente no desenvolvimento da competência informacional. No entanto, com base nas manifestações, tanto dos docentes quanto da bibliotecária, percebemos a necessidade da criação de políticas institucionais e de ações específicas que contribuam para a aproximação do trabalho pedagógico dos docentes, na sala de aula, e as ações que podem ser realizadas na biblioteca. Com isso, seria garantido mais um espaço pedagógico privilegiado e focado na aprendizagem e no desenvolvimento de competências, especialmente a competência informacional, uma aprendizagem necessária com relação aos desafios que os estudantes enfrentam na atual sociedade da informação. 


\section{CONSIDERAÇões FINAIS}

Nossa pesquisa teve como objetivo analisar as possibilidades de uma biblioteca configurar-se como espaço-tempo de aprendizagens e de desenvolvimento de competências informacionais. Nela, evidenciamos a importância da aprendizagem contínua e do desenvolvimento da autonomia de competências, em especial a informacional. A coleta e a análise de dados evidenciaram cinco categorias relacionadas à temática investigativa: acesso à informação, avaliação da informação, uso da informação, autonomia dos estudantes e possibilidades de atuação da biblioteca no desenvolvimento da competência informacional.

A pesquisa evidenciou, consoante a Vilela (2007), que é possível a renovação das instituições de ensino, nas quais seja viável desenvolver a autorreflexão crítica dos sujeitos, de modo a atingirmos a autonomia e a emancipação. Dessa forma, percebemos a pertinência de se estruturar experiências formativas, no âmbito das bibliotecas, e da atuação conjunta entre bibliotecários e docentes, que auxiliem os estudantes na obtenção da autonomia do refletir. Em relação a isso, o desenvolvimento da competência informacional pode contribuir, a partir da constituição de ações voltadas a capacitar os estudantes, desde a sua entrada na instituição, ao desenvolvimento da autonomia. Percebemos o potencial que ações desse tipo podem alcançar, desde que estejam inseridas, enquanto política institucional, na prática pedagógica e sejam trabalhadas em conjunto entre a biblioteca e os docentes.

Temos convicção de que a instituição escolar pode contribuir efetivamente para superar os obstáculos à autonomia, à emancipação e à reflexão crítica. Além disso, entendemos que o coletivo de educadores e de gestores de uma instituição educativa necessita desenvolver espaços que proporcionem experiências formativas que sejam capazes de contribuir na aprendizagem e no desenvolvimento dos discentes.

A biblioteca, como parte do ambiente educacional, pode se inserir nesse contexto como um dos espaços que proporcionam uma experiência formativa diferenciada, atuando como mediadora entre a informação e o estudante. Ao exercer esse papel de mediadora nos processos de busca e uso da informação, pode auxiliar o aluno a se formar a partir do acesso ao conhecimento e, por conseguinte, contribuir efetivamente no processo escolar.

Ao se propor a realizar, de maneira sistemática, atividades de capacitação para o desenvolvimento da competência informacional, a biblioteca passa a auxiliar os docentes na complexa tarefa de crescimento dos alunos. Assim, a biblioteca, conforme destaca Kuhlthau (2002, p. 10), tem a possibilidade de se constituir como um espaço no qual "[...] os recursos informacionais irão se constituir num rico manancial para propiciar o desenvolvimento de conhecimentos, habilidades e atitudes necessárias para viver e conviver na sociedade da informação".

Para realizar essa possibilidade educativa e em colaboração com os professores, a biblioteca necessita se tornar uma extensão da sala de aula e também um espaço de aprendizagem. Dessa forma, se possibilitarão aos alunos o acesso à informação de melhor qualidade e o aprendizado de estratégias de utilização das informações na resolução de dúvidas e de questões abordadas pelos professores em sala de aula. Para que de fato seja exercido esse 
papel, é necessário que haja uma parceria entre os profissionais da biblioteca e os docentes, o que possibilitaria ampliar significativamente as oportunidades de aprendizagem dos alunos.

Percebemos, por meio dos dados da pesquisa, que os docentes reconhecem a importância da biblioteca para o desenvolvimento da aprendizagem; no entanto, a percepção dominante parece a de que a biblioteca atua apenas como um espaço para pesquisa, consulta e empréstimo do acervo, e não como um espaço pedagógico. Destacamos que, para alterar essa percepção dos docentes, se faz necessária uma mudança na forma de atuação da biblioteca e do bibliotecário. Esses podem ser mais proativos, buscar parcerias com os docentes e manter um diálogo com a direção do campus, de forma a mostrar a importância de inserir a biblioteca no planejamento pedagógico.

A partir do conhecimento que possuímos em relação à realidade das bibliotecas escolares, acreditamos que os bibliotecários já possuem a preocupação ou a intenção de auxiliar no desenvolvimento dos alunos. Na pesquisa que realizamos, isso é observado tanto no questionário quanto na entrevista. Apesar da formação do bibliotecário ser mais voltada para a dimensão técnica, ao longo do curso de biblioteconomia também é desenvolvida a convicção de que a finalidade da biblioteca é a sua utilização e, para isso, deve-se facilitar o acesso do aluno à informação. Desse modo, a organização da biblioteca, o processamento técnico do material, os treinamentos para uso das bases de dados, normas e outros, todos são formas adotadas pelos bibliotecários para atuar como mediadores da informação.

Acreditamos que, por meio da atuação da biblioteca como espaço de aprendizagem, é possível desenvolver a capacidade dos estudantes de selecionar e de identificar adequadamente a informação, tornando-os mais autônomos e capazes. Reafirmamos, pois, no horizonte da pesquisa que temos realizado, a noção de que a biblioteca de uma instituição de ensino, como espaço-tempo de aprendizagem, cumpre relevante papel na formação dos estudantes, uma vez que pode contribuir significativamente no desenvolvimento da autonomia e de um conjunto de competências, especialmente a competência informacional.

No decorrer da pesquisa realizada, obtivemos várias manifestações da necessidade de capacitações voltadas para o desenvolvimento da competência informacional e relacionadas às questões do processo de busca. Além disso, os docentes percebem que existe na biblioteca e no bibliotecário a expertise necessária para desenvolver tais capacitações. Dessa forma, acreditamos na possibilidade de começar essa transformação pela realização de projetos de extensão com parceria dos docentes. Ao desenvolver um projeto de extensão que tenha como objetivo desenvolver a competência informacional e, por conseguinte, estimular o desenvolvimento da autonomia, criando condições para o aprender a aprender, entendemos que será possível demonstrar a capacidade da biblioteca de potencializar o processo de aprendizagem. Essa iniciativa pode auxiliar na aproximação do docente com a biblioteca e facilitar a inserção de atividades semelhantes na prática pedagógica institucional.

Ao inserir a biblioteca como um espaço de desenvolvimento da competência informacional, a atuação do bibliotecário estará mais relacionada ao trabalho de mediação. Sendo assim, o profissional terá que focar seu trabalho na criação, desenvolvimento e implantação de atividades que visem dar condições para a geração da competência informacional, 
da autonomia e do aprender a aprender. Esse tipo de atividade deve ser elaborado com a finalidade de educar os alunos para o acesso, a avaliação e o uso da informação. Com isso, seriam criadas oportunidades de desenvolvimento e de formação de um sujeito crítico a partir da qualificação da pesquisa acadêmica, com a ação conjunta dos docentes.

\section{REFERÊNCIAS}

ADORNO, Theodor W. Educação e Emancipação. Tradução: Wolfgang Leo Maar. Rio de Janeiro: Paz e Terra, 1995.

ALMEIDA, Jobson Louis Santos de. A biblioteca como organização aprendente: o desenvolvimento de competências em informação no Instituto Federal de Educação, Ciência e Tecnologia da Paraíba, 2015, 123 f. Dissertação (Mestrado Profissional em Gestão nas Organizações Aprendentes) - Programa de Pós-graduação da UFPB. João Pessoa, 2015. Disponível em: < http://tede.biblioteca.ufpb.br/handle/tede/7671>. Acesso em: 4 ago. 2016.

AMERICAN LIBRARY ASSOCIATION - ALA. Report of the Presidential Committee on Information Literacy: Final Report, 1989. Disponível em: http://www.ala.org/acrl/ publications/whitepapers/presidential. Acesso em: 22 dez. 2015.

BARDIN, Laurence. Análise de conteúdo. Lisboa: Edições 70, 2006.

BARI, Valéria Aparecida. A inclusão social e a competência informacional: uma situação universitária. Interdisciplinar. Ano 5, v. 10, p. 343-360, jan./jun. 2010.

BECKER, Fernando. Educação e construção do conhecimento. Porto Alegre: Artmed Editora, 2001.

BOFF, Daiane Scopel; ZANETTE, Carla Roberta Sasset. O desenvolvimento de competências, habilidades e a formação de conceitos: eixo fundante do processo de aprendizagem. In: CONGRESSO INTERNACIONAL DE FILOSOFIA E EDUCAÇÃO, 5, Caxias do Sul, 2010. Anais... Caxias do Sul: UCS, 2010. Não paginado. Disponível em: http://www. ucs.br/ucs/tplcinfe/eventos/cinfe/artigos/artigos/arquivos/eixo_tematico8/O\%20 DESENVOLVIMENTO\%20DE\%20COMPETENCIAS.pdf. Acesso em: out. 2015.

BRASIL, Lei n. 11.892, de 29 de dezembro de 2008. Institui a Rede Federal de Educação Profissional, Científica e Tecnológica, cria os Institutos Federais de Educação, Ciência e Tecnologia, e dá outras providências. Diário Oficial da União, Brasília, DF, 30 dez. 2008, p. 1. Disponível em: < http://www.planalto.gov.br/ccivil_03/_ato2007-2010/2008/ lei/111892.htm>. Acesso em: 20 out. 2016. 
CAMPELLO, Bernardete. Letramento informacional: práticas educativas de bibliotecários em escolas de ensino básico. Tese. Universidade Federal de Minas Gerais, 2009, 208f.

. Perspectivas de letramento informacional no Brasil: práticas educativas de bibliotecários em escolas de ensino básico. Encontros Bibli: Revista Eletrônica de Biblioteconomia e Ciência da Informação, Florianópolis, v. 15, n. 29, p. 184-208, 2010. Disponível em:

https://periodicos.ufsc.br/index.php/eb/article/viewFile/1518-2924.2010v15n29p184/19549. Acesso em 30 jun. 2015.

CAVALCANTE, Ricardo Bezerra; CALIXTO, Pedro; PINHEIRO, Marta Macedo Kerr. Análise de conteúdo: considerações gerais, relações com a pergunta de pesquisa, possibilidades e limitações do método. Inf. \& Soc.:Est., João Pessoa, v. 24, n. 1, p. 13-18, jan./ abr. 2014.

DUDZIAK, Elisabeth Adriana. A Information Literacy e o papel educacional das bibliotecas, 2001, 187 p. Dissertação (Mestrado em Ciência da Informação) - Escola de Comunicações e Artes, Universidade de São Paulo, São Paulo, 2001.

. Information literacy: princípios, filosofia e prática. Ciência da Informação, Brasília, v. 32, n. 1, p. 23-35, jan./abr. 2003.

EDER, K. As sociedades aprendem, mas o mundo é difícil de mudar. Lua Nova: Revista de Cultura e Política, São Paulo, 2001, n. 53, p. 5-28.

GASQUE, Kelley Cristine Gonçalves Dias. Letramento informacional: pesquisa, reflexão e aprendizagem. Brasília: Faculdade de Ciência da Informação/Unb, 2012. E-book. Disponível em: http://repositorio.unb.br/bitstream/10482/13025/1/LIVRO_Letramento_ Informacional.pdf. Acesso em: nov. 2015.

HABERMAS, J. Consciência moral e agir comunicativo, 2. ed. Rio de Janeiro: Tempo Brasileiro, 2003.

HABERMAS, J. Teoria do agir comunicativo, 1: racionalidade da ação e racionalização social. São Paulo: Martins Fontes, 2012.

KANT, Immanuel. Textos seletos, 3. ed. Petrópolis: Vozes, 2005.

KUHLTHAU, Carol Collier. Como usa a biblioteca na escola: um programa de atividades para o ensino fundamental. Belo Horizonte: Autêntica, 2002. 
. O papel da biblioteca escolar no processo de aprendizagem. In: VIANNA, Márcia Milton; CAMPELLO, Bernadete; MOURA, Victor Hugo Vieira. Biblioteca escolar: espaço de ação pedagógica. Belo Horizonte: EB/UFMG, 1999, p. 9-14.

MACEDO, Lino de. Competências e habilidades: elementos para uma reflexão pedagógica. Seminário do ENEM, 1999. Disponível em: <http://www.cefetsp.br/edu/eso/competenciashabilidades.html>. Acesso em: 13 mai. 2015.

. Competências na educação, 2008. Disponível em: http://www.rededosaber. sp.gov.br/contents/SIGS- CURSO/sigsc/upload/br/site_25/File/competencias_na_educacao.pdf. Acesso em: 26 jun. de 2015.

MARQUES, Mario Osorio. Aprendizagem: na mediação social do aprendido e da docência. Ijuí: Unijui, 2000.

MOUTINHO, Sônia Oliveira Matos. Práticas de leitura na cultura digital de alunos do ensino técnico integrado do IFPI - Campus Teresina Zona Sul, 2014, 183 f. Dissertação (Mestrado em Educação) - Faculdade de Educação. Universidade do Vale do Rio dos Sinos. São Leopoldo, 2014. Disponível em: http://www.repositorio.jesuita.org.br/bitstream/ handle/UNISINOS/3075/00000A51.pdf?sequence=1\&isAllowed=y. Acesso em: 4 ago. 2016.

PALANGANA, Isilda Campaner. Desenvolvimento e aprendizagem em Piaget e Vygotsky: a relevância do social. São Paulo: Summus, 2001.

PAVIANI, Jayme. Formação, ensino, aprendizagem e racionalidade ética. In: CENCI, Angelo V.; DALBOSCO, Cláudio A.; MUHL, Eldon H. (Org.). Sobre filosofia e educação: racionalidade, reconhecimento e experiência formativa [recurso eletrônico]. Passo Fundo: Ed. Universidade de Passo Fundo, 2013.

PERRENOUD, Philippe. Construir as competências desde a escola. Porto Alegre: Artmed, 1999.

PIAGET, Jean. Biologia e conhecimento. Lisboa: RES, 1978.

Epistemologia genética, 3. ed. São Paulo: Martins Fontes, 2007.

RIES, Bruno Edgar. A aprendizagem sob um enfoque cognitivista: Jean Piaget. In: LA ROSA, Jorge (Org.). Psicologia e educação: O significado do aprender, 8. ed. Porto Alegre: EDIPUCRS, 2004. 
SILVA, Helena et al. Inclusão digital e educação para a competência informacional: uma questão de ética e cidadania. Ciência da Informação, Brasília, v. 34, n. 1, p. 28-36, jan./ abr. 2005.

SOUZA, Margarida Maria de. A biblioteca universitária como ambiente de aprendizagem no ensino superior, 2009, 90 f. Dissertação (Mestrado em Ciência da Informação) - Escola de comunicações e Artes, Universidade de São Paulo, São Paulo, 2009.

VARELA, Aida. A explosão informacional e a mediação na construção do conhecimento. In: ENCONTRO NACIONAL DE PESQUISA EM CIÊNCIA DA INFORMAÇÃO (ENANCIB), 6, 2005, Florianópolis. Anais eletrônico... Florianópolis: IBICT, 2005. Disponível em: http://enancib.ibict.br/index.php/enancib/vienancib/paper/view/1755/896. Acesso em: nov. 2015.

VILELA, Rita Amelia Teixeira. Críticas e possibilidades da educação e da escola na contemporaneidade: lições de Theodor Adorno para o currículo. Educação em Revista, Belo Horizonte, v. 45, p. 223-248, jun. 2007. Disponível em: http://www.scielo.br/scielo. php?pid=S0102-46982007000100012\&script=sci_arttex. Acesso em 7 jun. 2015.

YIN, Robert K. Estudo de caso: planejamento e método, 2. ed. Porto Alegre: Bookman, 2001.

\section{DAdOS DOS AUTORES}

\section{Luciane Alves Santini}

Doutorando do Programa de Pós-Graduação em Educação e Ciências da Universidade Federal do Rio Grande do Sul (UFRGS). Mestre em Educação pelo Programa de Pós-Graduação em Educação do Unilasalle de Canoas (2016). Especialista em Ciência da Informação pela Universidade da Região da Campanha (URCAMP - 2010). Graduada em Biblioteconomia pela Fundação Escola de Sociologia e Política de São Paulo (FESP - 2003). Atua como bibliotecária-documentalista no Instituto Federal do Rio Grande do Sul (IFRS) desde 2013 desenvolvendo atividades de processamento técnico, administração da biblioteca, desenvolvimento de coleção, promovendo treinamentos e capacitações para a comunidade acadêmica e coordenando o Programa Litera Mundo para o desenvolvimento da leitura e cidadania. Contato:luciane.santini@viamao.ifrs.edu.br

\section{Cledes Antonio Casagrande}

Doutor em Educação pela Pontifícia Universidade Católica do Rio Grande do Sul (PUCRS - 2012). Mestre em Educação nas Ciências pela Universidade Regional do Noroeste do 
Estado do Rio Grande do Sul (UNIJUI - 2008). Licenciado em Filosofia pela Universidade La Salle (2003). Atualmente é docente no PPG em Educação da Universidade La Salle, de Canoas, RS, Pró-Reitor de Pós-Graduação Pesquisa e Extensão e Vice-Reitor dessa mesma instituição. Tem experiência na área da Educação, atuando principalmente nos seguintes temas: educação, filosofia da educação, teorias da educação, cultura, hibridismo tecnológico, aprendizagem, práxis pedagógica, linguagem e ética. Contato: cledes.casagrande@ unilasalle.edu.br

Submetido em: 1-7-2017

Aceito em: $23-4-2018$ 